\title{
DILTHEY: HERMENÊUTICA DA VIDA E UNIVERSALIDADE PEDAGÓGICA
}

\author{
Maria Nazaré de Camargo Pacheco Amaral
}

\begin{abstract}
RESUMO: Dilthey apontou primeiro a psicologia e depois a hermenêutica como tendo papel fundamental para sua filosofia da vida, cujo principal objetivo prático é desenvolver a pedagogia ou teoria geral da educação. A pedagogia necessita da ajuda da ética para estabelecer seus fins e da psicologia para indicar seus meios. Este texto tem por objetivo mostrar a relação entre hermenêutica da vida e pedagogia, para Dilthey. A filosofia da vida do autor, ao adotar procedimento hermenêutico, exercita a compreensão ou busca de significado das criações humanas histórico-sociais por um tipo especial de relação entre as partes e o todo. É justamente dentro desse balanço hermenêutico que propomos apagar qualquer vestígio de ruptura, brecha ou contradição entre a busca de princípios universais da ação humana e a impossibilidade de construção da tarefa humana moral, por meio de princípios universais. Só em 1890 Dilthey deu início às conhecidas conferências sobre ética, na Universidade de Berlim. Tais conferências, publicadas em 1958 por Herman Nohl, no volume X das Obras Completas, apontam as diretrizes do caminho que deverá consolidar a ética formativa ou social, enquanto solução histórica para o alcance de princípios universais de orientação para a conduta humana. Essa trajetória efetiva-se graças ao exercício distintivamente humano da autorreflexão. Por meio dela, é possível cumprir nosso destino de manifestar, exteriorizar no tempo a energia do espírito absoluto que nos é imanente. Diante desse panorama, este texto procura sublinhar como é possível que tal pedagogia possa respeitar sua tarefa universal de orientar historicamente o desenvolvimento das novas gerações, sem dirigir o processo por meio de fins rígida e fixamente estabelecidos.
\end{abstract}

PALAVRAS-CHAVE: Pedagogia universal. Autorreflexão. Ética formativa. Filosofia da vida. Hermenêutica.

O caminho da "descrição da vida" ou da "crítica da razão histórica" confunde-se em Dilthey com o da formação teórica do mundo histórico. O procedimento hermenêutico, defendido por Dilthey como o mais apropriado para a compreensão do mundo histórico do espírito, fundamenta-se no reforço do

\footnotetext{
${ }^{1}$ Professora Titular do Departamento de Filosofia e Ciências da Educação da Faculdade de Educação da Universidade de São Paulo. E-mail: namaral@usp.br
} 
balanço pendular entre todo e parte, universal e singular. "Eu devo compreender o todo - declara Dilthey - a partir do singular e o singular a partir do todo. Dessa contradição resulta o procedimento do hermeneuta" ${ }^{2}$. As relações vivas entre o reino das uniformidades, dos casos típicos, e o reino do singular, dos casos particulares, da individuação, compõem a marcha da história, marcha essa que define a própria natureza do trabalho hermenêutico das ciências do espírito. $\mathrm{O}$ ponto crítico deste traduz-se assim para o autor: "[...] a partir do conhecimento do geral, que se apóia na abstração das diferenças próprias do homem singular, aproxima-se do grande problema da individuação" " E, só para compor o outro polo do movimento pendular, o acesso à individuação só nos é possível pela via indireta do conhecimento do geral, que, por sua vez, se apoia nas diferenciações próprias do homem singular, concreto... Nosso propósito fundamental será o de procurar mostrar algumas raízes mais profundas da hermenêutica da vida, enquanto capazes de impulsionar e orientar a filosofia da vida de Dilthey, em sua trajetória teórica, de descrever a vida pelo exercício do balanço pendular entre todo e parte, universal e singular, vida e história, teoria e prática, pensar e agir, filosofia e pedagogia. Com base, então, na perspectiva diltheiana da vida, buscaremos aprofundar as relações de compromisso funcional entre filosofia e pedagogia.

\section{Filosofia PRÁticA OU ÉTICA SOCIAL: UMA SOLUÇÃo HISTÓRICA}

Todo arcabouço histórico construído pela trajetória diltheiana da crítica da razão histórica parece ter apenas um valor instrumental, pois ele está, desde suas origens, voltado para consolidar a satisfação de uma necessidade anterior à teórica, primitiva por origem, a saber, a necessidade humana de segurança prática. É como se a filosofia da vida, símbolo máximo da busca da certeza teórica, resultasse da necessidade essencialmente humana de buscar apoio sólido para a ação e, com isso, permitisse extrair de toda sua especulação teórica regras práticas ou orientação de conduta. Dilthey é bem claro, quando afirma: "A última palavra do filósofo [...] é a pedagogia, pois toda especulação é feita devido ao agir"' . A tarefa pedagógica constitui para ele o fim prático por excelência de toda filosofia que mereça respeito. "A florescência e o objetivo de toda verdadeira filosofia" - continua o autor - "[...] é a pedagogia, em sentido mais amplo, teoria da formação do homem"5.

\footnotetext{
${ }^{2}$ DILTHEY, W. Logik und System der philosophischen Wissenschaften. In: vol. XX, p. 107.

3 Obras Completas, V, 268.

4 Pädagogik, Geschichte und Grundlinien des Systems, Obras Completas, IX, 1.

5 Ibid., p. 7.
} 
A história da publicação dos trabalhos de Dilthey sobre pedagogia é a mesma de todos os demais, isto é, em vida veio a público, fora um estudo sobre Süvern, apenas o conhecido tratado Sobre a Possibilidade de uma Ciência Pedagógica com Validez Universal (1888). Costuma-se destacar dois surtos de interesse do autor pelo tratamento de questões pedagógicas ou da história da pedagogia. No período em que lecionou em Breslau, verão de 1874: "História da Pedagogia com Emprego da Psicologia para a sua Preparação Sistemática"; no inverno de 1874/75: "História da Pedagogia e Fundamentos de seu Sistema", e, no inverno de 1878/79: "História do Ensino Prussiano". O período seguinte de interesse do autor por assuntos pedagógicos foi o de seu professorado em Berlim, entre o verão de 1884 e o de 1894. Durante esse tempo, lecionou "História e Sistema de Pedagogia" e "Emprego da Psicologia para a Pedagogia", como complemento da conferência sobre psicologia. Esses trabalhos foram aos poucos sendo publicados ao lado de outros, em diferentes volumes das Obras Completas de Dilthey, incluindo-se principalmente os volumes III, IV e especialmente o VI, onde se encontra reeditado o conhecido tratado publicado em vida: Sobre a Possibilidade de uma Ciência Pedagógica com Validez, Universal. Destacamos, além destes, o volume IX, por incluir apenas trabalhos sobre pedagogia, recebendo, assim, o título de Pedagogia, História e Fundamento do Sistema ou, resumidamente, Pedagogia, publicado por Otto Friedrich Bollnow, em 1924, onde está incluído o ciclo de conferências de Berlim, que, por sua vez, devido à natureza do assunto, se liga à fase de elaboração pedagógica em Breslau ${ }^{6}$.

Com esses trabalhos, Dilthey conquista um lugar de destaque como um dos principais representantes da renovada reflexão pedagógica na Alemanha. Em poucas palavras, Theodor Wilhelm, no capítulo "O caminho da ciência pedagógica" de seu livro A Pedagogia do Presente, nos dá uma visão ampla e lúcida da posição diltheiana, dentro do movimento renovador da educação na Alemanha, em finais do século XIX e começo do XX:

Nas quatro décadas entre 1890 e 1930 a pedagogia conquistou seu reconhecimento definitivo no círculo das ciências. O progresso não se deixa fixar em uma determinada data de nascimento. Nem o tratado de Dilthey "Sobre a Possibilidade de uma Ciência Pedagógica de Validez Universal”, de 1888, nem o sistema das "Formas de Vida" de Spranger, de 1914, ou a "Teoria da Formação" de Kerschensteiner, de 1926, nem o "Indivíduo e a Comunidade" de Litt, de 1919, nem o grande "Manual de Pedagogia" com o qual Herman Nohl, entre 1928 e 1933, tentou consolidar a autonomia da pedagogia, nem a infiltração da empiria científica da natureza no conhecimento da juventude, nem as exigências opressivas da pedagogia vocacional, nem os resultados positivos da psicologia experimental,

\footnotetext{
${ }^{6}$ Destacamos também dois projetos de pedagogia publicados pela primeira vez por Herman Nohl, in: Kleine pädagogische Texte, caderno 3, 1. ed., Langensalza 1930; 4. ed. Weinheim 1963, p. 3-8.
} 
com os impulsos da filosofia da vida ou a exploração fenomenológica do mundo objetivo espiritual podem por si sós reivindicar o mérito. Todas essas posições precisam ser melhor avaliadas em conjunto como sinais e testemunhas de uma ruptura que precisava ter lugar quando uma transformação social, política e espiritual de 200 anos tinha abalado a tradicional compreensão da pedagogia. ${ }^{7}$

Conforme pudemos observar, o processo de conquista de reconhecimento científico por parte da pedagogia não se deixa apreender em uma data fixa e só pode ser compreendido se levarmos em conta diferentes fatores, não só de ordem espiritual, mas política e social. Embora esse resumido, porém lúcido, rol de informações e caminhos de pesquisa sugeridos por Theodor Wilhelm confira a Dilthey lugar de destaque dentro do movimento de renovação pedagógica, no período de 1890 e 1930, não podemos a partir daí defender a existência de unanimidade de opiniões a respeito da postura pedagógica do autor. Pelo contrário, alguns de seus contemporâneos manifestaram grande insatisfação desde a publicação, em 1888, de seu conhecido tratado Sobre a Possibilidade de uma Ciência Pedagógica com Validez Universal. Esse tratado teria dado motivo, julgavam eles, para uma desqualificação científica da pedagogia e, com isso, teria causado a rejeição de cadeiras de pedagogia nas universidades de Munique, Würzburg e Erlangen Entre os críticos, Otto Willmann parece destacar-se, ao resumir em poucas palavras o motivo essencial de seu descontentamento com a posição diltheiana implícita naquele tratado de 1888: "O que Dilthey reconhece como pedagogia universal é sem vigor e indefinido porque ele não admite a validade de nenhum sistema de princípios como seu fundamento último", O mesmo Willmann, em carta ao contemporâneo Wilhelm Rein, fez outro comentário aos enunciados pedagógicos de Dilthey: "Estes não me causam aliás qualquer admiração, visto que Dilthey, em sua Introdução às Ciências do Espirito, já está a meio caminho para o cepticismo e para ele não resta muito mais, tanto da filosofia quanto da pedagogia" ${ }^{\prime 10}$.

De fato, a pedagogia diltheiana, resultado prático mais elevado de sua "filosofia da vida”, não poderia contrariar os postulados básicos do trabalho teórico que a precede e que, por sinal, deve devidamente sustentá-la. Nesse caso, é inteiramente indefensável, para Dilthey, o domínio de sistemas de pedagogia que buscam princípios

\footnotetext{
${ }^{7}$ WILHELM. Theodor. Pädagogik der Gegenwart, Vol. 248, 3. ed. Stuttgart: Kröner Taschenausgabe,1963, p. 117.

8 Cf. HERMANN, Ulrich. Die Pädagogik Wilhelm Diltheys. Ihr wissenschaftstheoretischer Ansatz in Diltheys Theorie der Geisteswissenschaften. Göttingen: Vandenhoeck \& Ruprecht, 1971, p. 25.

9 WILLMANN, Otto. Die Fundamentalbegriffe der Erziehungswissenschaft. 1. Jahrbuch für christliche Erziehungswissenschaft, Kempten, p. 38, 1908.

${ }^{10}$ Cf. Hartong, Konrad. Der Begriff der "paedagogia perennis" und die Auseinandersetzung Otto Willmanns mit Wilhelm Dilthey. Paedagogica Histórica, 3. Jg., Gent, p. 285, 1963.
} 
universalmente válidos para a educação de todos os povos, em todas as épocas ${ }^{11}$. A pedagogia deve extrair da ética o conhecimento de seu objetivo e da psicologia o conhecimento dos meios, isto é, dos processos psíquicos, o que lhe permitirá atingir com segurança o seu fim. Até o momento, nenhuma grande inovação para a pedagogia alemã da época. O fim da educação só pode ser apreendido pela ética no fim da vida, com uma importante e, ao que parece, inovadora ressalva, isto é, sem nenhuma pretensão de validade universal. Declara Dilthey:

Só do fim da vida pode ser derivado o fim da educação, mas este fim da vida não pode a ética determinar com validade universal. Isto pode já ser diagnosticado pela história da moral. O que o homem é o que quer ele o experimenta apenas no desenvolvimento do seu ser através dos séculos e nunca de forma definitiva, nunca em conceitos de validade universal, senão sempre, somente nas experiências vivas que surgem do fundo de todo seu ser. Pelo contrário, toda fórmula de conteúdo sobre o fim último da vida mostrou-se condicionada historicamente. Nenhum sistema moral pôde conquistar até agora reconhecimento universal. ${ }^{12}$

Com efeito, não parece ser de todo necessária uma análise engenhosa ou arguta dessas formulações diltheianas sobre a pedagogia, para podermos detectar sinais evidentes de um relativismo pedagógico. À primeira vista, não há como fugir às ponderações de Willmann de que aquilo que Dilthey admite como pedagogia universal é totalmente sem substância e permeado por indefinições, uma vez que se recusa a admitir qualquer universalidade de princípios. O julgamento de Willmann, todavia, não se limita à pedagogia diltheiana, pois desfere golpes, na aparência, fatais a sua filosofia, à medida que acusa a primeira exposição sistemática de sua filosofia, isto é, a Introdução às Ciências do Espírito, de estar a meio caminho do cepticismo.

$\mathrm{Na}$ verdade, essa crítica não nos é de modo algum estranha, mas, se acompanharmos o desvelar da tarefa da consciência histórica dentro do pensamento diltheiano, assistiremos à alteração de sua posição diante da filosofia, isto é, de "adversária" ou inimiga (porque apontou energicamente a relatividade de todo fenômeno histórico) passou a sua "médica" salvadora". Ora, se a consciência histórica soube como ninguém curar a ferida do relativismo que ela própria produzira, enquanto, levada às suas últimas consequências, se volta para si mesma, se autorreflete, permitindo-nos captar por trás de toda relatividade

11 Cf. Pädagogik, Gesammelte Schriften, IX, 167; Über die Möglichkeit einer allgemeingültigen pädagogischen Wissenschaft, VI, 56-57.

12 "Über die Möglichkeit einer allgemeingültigen pädagogischen Wissenschaft", Gesammelte Schriften, VI, 57.

${ }^{13}$ Cf. Das geschichtliche Bewusstsein und die Weltanschauungen, Obras Completas, VIII, 10. 
superficial a soberania absoluta do espírito ${ }^{14}$; por conseguinte, ser-nos-á possível sentir igualmente no âmbito do discurso pedagógico os efeitos positivos desse processo valioso de autocura. Dentro desse campo da "teoria da formação do homem", ou pedagogia, ou mesmo, da ética, a grande responsável pelo estabelecimento de fins para a educação, o pronto restabelecimento da ferida do relativismo representaria o reconhecimento de uma pedagogia substanciosa e solidamente definida, capaz de orientar universalmente os passos do educador, que, desse modo, não estaria irremediavelmente preso aos contornos pobres e mesquinhos delineados pelos condicionamentos históricos sempre tão funcionais e pragmáticos, mas extremamente limitados. Afinal, a consciência histórica, como "médica" salvadora da filosofia, liberta o homem tão radicalmente de todos os relativismos e condicionamentos inerentes a toda sua tradição cultural - inclua-se aqui filosofia, religião ou ciência -, que é como se ela o libertasse de si mesmo, de sua história, para devolvê-lo à totalidade, à soberania absoluta do espírito e, somente nessa relação parte-todo, lhe permitisse extrair o significado de suas experiências limitadas de vida ${ }^{15}$.

Para acompanhar os efeitos causados pela reabilitação da filosofia no âmbito da pedagogia - já que aquela existe em função desta - cumpre-nos recobrar as considerações de ordem ético-pedagógica do autor. Como sabemos, cabe à ética derivar do fim da vida o fim da educação. Nesse sentido, o autor é categórico e não admite nenhuma possibilidade de a ética determiná-lo universalmente, alegando que a própria história da moral está diante de nós para garantir o referido diagnóstico. Em sua opinião, ela nos mostra que nenhum sistema moral recebeu até hoje reconhecimento universal, porque toda fórmula usada para exprimir o fim último da vida envolve sempre uma interpretação, e esta é sempre produto de um condicionamento histórico. "Como nós não possuímos um princípio metafísico explicador do mundo de validade indiscutível - sustenta Dilthey -, só podem assim ser extraídos princípios da vida moral das emoções e impulsos vivos, tais como a simpatia, a aspiração à perfeição e à felicidade e o sentimento de dever que estão em relação recíproca. Mas, a apreensão conceitual desses impulsos e a relação das fórmulas assim nascidas como um todo constituem sempre uma

\footnotetext{
${ }^{14}$ Cf. Obras Completas, VII, 290-291.

${ }^{15}$ Para maior aprofundamento da questão das relações entre consciência histórica e espírito soberano, cf. AMARAL, M. Nazaré C. P. Philosophie der Philosophie: ein wirksames Pflaster zur Heilung der vom historischen Relativismus geschlagenen Wunde? In: RODI, Frithjof (Org.). Dilthey-Jahrbuch für Philosophie und Geschichte der Geisteswissenschaften, vol. VI. Göttingen: Vandenhoeck \& Ruprecht, , 1983, p. 277-291.
} 
interpretação das mesmas, e uma tal interpretação está sempre condicionada ou limitada historicamente como um ideal ou sistema ético"16.

Com essas formulações tão categóricas, Dilthey termina por colocarse em uma situação verdadeiramente embaraçosa, porque fundamentalmente conflitante para quem tem fortes aspirações de conciliação. Se, de um lado, ele não admite a validade universal de princípios éticos, de outro, sustenta que uma filosofia só pode ser verdadeira, se for capaz de extrair de seus conhecimentos teóricos princípios universais de orientação de vida para o indivíduo e para a sociedade. Uma questão de vital importância para suas considerações sobre a ética permanece sem resposta: "Que prudentes e delimitadas operações de entendimento são possíveis para tão bem conseguirmos princípios universais da filosofia prática? A velha filosofia está morta. Talvez seja possível uma outra solução histórica"17. Vejamos, portanto, de que modo a solução histórica proposta por Dilthey pretende ser uma solução para essa questão, e se isso é de alguma forma possível, sem ferir aqueles limites inicialmente impostos pelo autor para o tratamento do problema ético. Em outras palavras, como será possível ao autor resolver esse impasse entre o objetivo da filosofia e as delimitações que circunscrevem o ponto de partida de seu próprio exercício.

Em relação à importância que a ética tem para o pensamento diltheiano, cabe-nos salientar que ele começa a sua produção científica com trabalhos sobre ética, incluindo, em 1864, sua tese de doutoramento: "De Principiis Ethicis Schleiermachi" e seu trabalho de livre-docência "Tentativa de uma Análise da Consciência Moral". O primeiro tem a sua segunda parte traduzida para o alemão e publicada no volume XIV da Obras Completas, em 1960, enquanto o segundo é publicado em 1924, no volume VI das Obras Completas do autor. No mesmo ano, vem também a público o volume $\mathrm{V}$, que inclui, entre outros, um ensaio "Sobre o Estudo da História das Ciências do Homem, da Sociedade e do Estado”, de 1875, onde Dilthey tenta relacionar a moral com as outras ciências da sociedade e, a partir desse ponto, praticamente antevê seu desenvolvimento como ética social.

Só em 1890 deu início às conhecidas conferências sobre ética, na Universidade de Berlim. Nessas conferências, publicadas em 1958 por Herman Nohl, no volume X das Obras Completas, Dilthey como que estabelece as diretrizes do caminho que deverá conduzi-lo àquela solução ética que, embora histórica, responderá pelo alcance de princípios universais para a orientação da conduta humana. Para que isso seja possível, é preciso que o autor supere ou transcenda a antinomia inerente a essa sua proposição, isto é, como uma solução historicamente

\footnotetext{
16 Über die Möglichkeit einer allgemeingültigen Wissenschaft, Gesammelte Schriften, VI, 57.

${ }^{17}$ System der Ethik, Gesammelte Schriften, X, 117.
} 
condicionada poderá romper a barreira da limitação natural da ética diltheiana para alcançar a universalidade de princípios éticos? E a referida solução parece deixar-se apreender formalmente, na seguinte afirmação do autor: "A ética do presente precisa ser uma ética social" ${ }^{\prime 18}$.

A ética diltheiana, já em sua estrutura constitucional, encontra-se comprometida com o conceito de vida, uma vez que ela deve extrair do fim da vida o fim da educação. A pedagogia é, como sabemos, o mais elevado destino da ciência e da filosofia e, enquanto tal, o ponto central de desembocadura de todo o caudal de investigações filosóficas do autor sobre a vida. A ética social, proposta por ele como uma solução histórica apta a alcançar princípios universais de conduta humana, encontra-se, do mesmo modo que a pedagogia e a "filosofia da vida" - uma filosofia vitalmente prática -, inteiramente subordinada àquilo que o autor denomina nexo estrutural imanentemente teleológico da vida. "A tendência finalista, enquanto qualidade fundamental da vida psíquica, nos é dada como fato primário". ${ }^{19}$ A teleologia da vida psíquica constitui o elo que sustenta, portanto, a unidade das funções psíquicas, a unidade da vida. Esta se exercita como reação ou movimento dirigido a um estímulo ou impressão que vem do meio em que o ser vivo se encontra, resultando na adaptação daquele ser ao meio. Aqui está, para o autor, a célula original da vida interior. ${ }^{20} \mathrm{E}$ o homem, esse verdadeiro "feixe de impulsos", conforme Dilthey com muita insistência o qualifica, tem sua organização vital presa a esse esquema original fundamental, próprio dos seres vivos em geral. Todas as atividades humanas e o comportamento do homem estão sujeitos ao processo de desdobramento das condições simples e primitivas às mais complexas e ricas. Isso quer dizer que não apenas a habilidade produtiva do homem, mas também sua conduta ética estão sujeitas a essa lei universal do crescimento. Esta atua como uma "força uniforme" que impulsiona todo o ser vivo a cumprir espontaneamente seu destino.

Apoiados nessas considerações, não nos é difícil compreender que Dilthey se insurja contra o que ele denomina "ética negativa" e "ética restritiva", colocando-se em defesa de uma ética formativa. Se o homem é "um feixe de impulsos", isso não significa que o comportamento humano para ser moral tenha necessidade de repudiar por completo toda "animalidade psíquica" (ética negativa), nem mesmo de exercer pressão sobre ela (ética restritiva), mas sim

\footnotetext{
18 Ibid., 13.

19 Übersicht meines Systems, VIII, 180.

20 Cf. Leben und Erkennen, Gesammelte Schriften, XIX, 345.
} 
de formá-la por meio do regime ${ }^{21}$. "O meio de moldar a animalidade psíquica em uma forma de vida alegre, concordante com a vida mais elevada" - declara Dilthey -, " "...] reside no regime, tomando-se a palavra em sentido amplo. [...] A moderação e direção correta da alimentação e o reforço dos exercícios corporais e atividades são os verdadeiros meios de conservar-se a alegria da vida em um corpo saudável e o impulso da raça em sua forma moderada"22.

De fato, para que imposições, restrições ou proibições exteriores, se o ser vivo conta com o apoio daquela energia que emana do seu interior, energia capaz de garantir-lhe uma vida saudável, desde os níveis mais simples e rudimentares aos mais ricos e complexos da escala biológica? Como sabemos, no nível mais elevado dessa linha de evolução encontra-se o homem, o único ser vivo que tem consciência desse nexo, dessa unidade original, isto é, de sua vida ao mesmo tempo enquanto parte e enquanto todo. E o viver humano traduz-se, assim, no contínuo exercício da consciência de si mesmo, identificando-se, por conseguinte, com o que Dilthey denomina autorreflexão. Dentro da perspectiva da ética formativa proposta por Dilthey, a autorreflexão passa a representar o símbolo máximo da virtude moral, uma vez que o homem, ao praticá-la, estará conscientemente submetendo-se ao regime moral, tornando-se prudente e moderado, fazendo, desse modo, jus à alegria autêntica de uma vida plenamente saudável.

Por esse verdadeiro lançamento da pedra fundamental da ética diltheiana, não há por que falarmos em repressão da natureza, luta ou conflito entre animalidade e espiritualidade. Se voltamos a insistir nesse ponto é porque Dilthey nos assegura que a sua ética formativa, diferentemente daquela de Schleiermacher, tem uma "fundamentação concreta" e contrária à ética negativa e restritiva, pretendendo superar o dualismo entre vontade "sinônimo de elevada animalidade" e "vontade espiritual" 23.

Na verdade, não há lugar aqui para rupturas, brechas ou separações, pois tudo emana da força soberana de uma energia original. Aqui parece residir toda aquela concretude de fundamentação da ética formativa de Dilthey, isto é, o comportamento moral flui naturalmente do exercício distintivamente humano da autorreflexão. Por meio dele, o homem vivencia revivendo a sua religação com o espírito absoluto. Essa é a base autenticamente viva e concreta da ética formativa,

\footnotetext{
${ }^{21}$ O princípio da formação da vida impulsiva encontra-se, na opinião de Dilthey, expresso de modo muito abstrato pela ética formativa de Schleiermacher. Como exemplo de ética restritiva, ele cita Stoa e Kant e, como representante da ética negativa, ele destaca os neoplatônicos, a comunidade cristã, os budistas e Schopenhauer. Cf. System der Ethik, Gesammelte Schriften, X, 59.

${ }^{22}$ Ibid.

${ }^{23}$ Cf. Ibid.
} 
segundo a versão de Dilthey. Este declara, de maneira taxativa, que "[...] a ética só é possível sobre a base da autorreflexão" 24 , Como sabemos, o princípio da autorreflexão encontra-se totalmente amparado pela "força uniforme"que dirige teleologicamente a vida, permitindo a quem o pratica cumprir de modo autêntico seu destino de manifestar, exteriorizar a energia absoluta que lhe é imanente: "A teleologia da vida psíquica nos mostra que o agir humano exige e necessita de um ponto absoluto na mente, se é que este agir quer estar seguro de si mesmo. E como a vida psíquica afirma-se em suas experiências vivas, como um nexo teleológico, assim são incluídos nessa mesma forma de nexo todos os acontecimentos dependentes dela. O absoluto abarca todos eles nessa forma de nexo"25.

O fato de Dilthey admitir que o absoluto apreende, sob a forma de nexo, tudo que acontece na vida psíquica, não significa que esteja abrindo qualquer exceção ao seu princípio ético fundamental, qual seja, “[...] o que é moral não pode ser respondido a prior" " 26 . Conforme estamos procurando evidenciar, a base da ética formativa deve ser a experiência concreta, ou seja, os padrões morais não são impostos pela força de imperativos categóricos, mas são vivenciados dentro da evolução histórica da humanidade. Eles têm vida, não são apenas fórmulas vazias e mortas destinadas a apreender e subjugar em suas tramas todo conteúdo vivo do comportamento humano. Com toda a firmeza, Dilthey declara: "Há, em realidade, somente uma ética que se constrói de baixo e não uma que se desenvolve de cima"27. E uma moral que se organiza de baixo para cima é uma moral que resulta do exercício amplo e efetivo de todas as forças psíquicas, incluindo desde as mais elementares e primitivas até as mais complexas e diferenciadas.

"Não há" - insiste Dilthey - "[...] nenhuma construção da tarefa moral do homem por meio de conceitos universais. Não há nem uma base metafísica, nem uma empírica para semelhante construção. Em última instância, não se pode construir uma vida nem das emoções mais elementares e inferiores, nem dos elementos morais mais elevados" 28 . Como podemos perceber, Dilthey prossegue perseverando em seu intento de recriminar qualquer tentativa de construir abstratamente a tarefa humana moral. Será que o fato de Dilthey abominar qualquer pretensão ou mesmo aspiração humana de construir universalmente os conceitos morais constitui obstáculo intransponível para que a sua filosofia da vida, enquanto ética social ou substituta autêntica da velha filosofia prática

\footnotetext{
${ }^{24}$ Ibid., 27.

25 Gesammelte Schriften, IX, 225.

${ }^{26}$ Cf. System der Ethik, Gesammelte Schriften, X, 87.

27 Ibid., 112.

${ }^{28}$ Ibid., 117.
} 
ou pedagogia, alcance os princípios universais capazes de orientar a conduta humana? Todavia, como sustentar uma continuidade harmoniosa entre dois polos tão opostos? Lembramos que a "filosofia da vida", ao adotar procedimento hermenêutico, exercita a compreensão ou a busca de significado das criações humanas histórico-sociais por um tipo especial de relação entre as partes e o todo.

É justamente dentro desse balanço hermenêutico que nos propomos apagar qualquer vestígio de ruptura, brecha ou contradição entre o objetivo primordial da filosofia prática e as delimitações que ajudam a compor seu próprio ponto de partida. Em outras palavras, procuraremos mostrar de que modo tão sutil não existe contradição entre a busca de princípios universais da ação humana e a impossibilidade de construção da tarefa humana moral por meio de conceitos universais. A questão não parece ser tão intrincada, como à primeira vista se nos apresenta. É preciso inicialmente levar em consideração que a tarefa moral não é, para Dilthey, uma tarefa a ser cumprida pela atividade do indivíduo particular, mas sim pelo esforço do gênero humano em seu evoluir histórico, porque a existência humana se revela muito limitada para satisfazer as exigências próprias da natureza ${ }^{29}$. Essas necessidades naturais, ao serem criativamente satisfeitas ao longo da evolução da humanidade, ajudam a escrever a própria história universal do gênero humano.

Talvez não seja demasiado insistir que essas exigências inerentes à natureza humana advêm daquele nexo ou união entre vivência histórica e a fonte de energia infinita, o que faz da singularidade do vivenciar apenas um modo humanamente limitado de manifestar ou exteriorizar o compromisso original com a unidade espiritual, com o universal. "Nós precisamos" - acentua Dilthey, em seu Sistema de Ética (1958) - “[...] interrogar a evolução moral e, em diferentes épocas, ela nos dá uma resposta consideravelmente diferente. Os agentes, que possibilitam contínua satisfação e um estado sentimental elevado, nós designamos inicialmente como forças morais. Mas a moralidade ou o próprio bem só é, pois, aquilo que a evolução plasmou"30. Dizer que o bem resulta de forças morais plasmadas pela evolução não constitui, a nosso ver, dada a particularidade do caso em questão, motivo suficiente para coibir a esperança da filosofia prática de conquistar princípios universais para a conduta humana.

Da mesma forma, quando Dilthey nos assegura, como já vimos, que nenhum sistema moral pôde, até hoje, conquistar reconhecimento universal, não devemos extrair daí uma postura relativista e muito menos céptica do autor do problema moral. Afinal, ele não cansa de insistir que o que o homem é ou quer ele

\footnotetext{
29 Cf. Einleitung, Gesammelte Schriften, I, 44.

${ }^{30}$ Gesammelte Schriften, X, 87.
} 
o manifesta em "[...] experiências vivas que surgem do fundo de todo seu ser" 31 , E nós sabemos que, se seguirmos essa direção indicada pelo autor, depararemos, no mais fundo de nosso ser, com aquele nexo, símbolo da ligação original da vida histórica de seres humanos singulares com a vida infinita do espírito universal. É justamente a partir dessa união com a energia espiritual que o gênero humano tem condições de plasmar em seu evoluir histórico as forças morais que devem orientar universalmente a ação humana individual e social. Aqui parece residir o sentido mais profundo da ética socialmente formativa defendida por Dilthey.

Trata-se, na verdade, de um processo histórico de formação dos padrões morais que, em cada época, deverão reger o comportamento humano em sociedade. Como sabemos, as regras morais só têm valor se forem extraídas do calor vivo das experiências humanas, em seu evoluir historicamente condicionado. No entanto, como já é de nosso conhecimento, esse calor de vida, que advém das vivências, tem como fonte original uma energia infinita, esta sim a única a garantir àquelas o caráter de universalidade autêntica. De fato, a história traduz no tempo a eternidade da vida do espírito infinito.

Quando Dilthey defende a necessidade de a ética de seu tempo caminhar em direção a uma ética social, ele parece ter em mente um novo conceito de subjetividade. Trata-se, como estamos procurando demonstrar, do homem que tem consciência de que cada ato seu representa em si uma religação consoladora e protetora com o todo ao qual pertence e que, em certo sentido, também lhe pertence. Ora, a vida humana em sociedade parece constituir para o autor o símbolo vivo e historicamente concretizável dessa unidade original. E o exercício humano da autorreflexão histórica, qual seja, o dobrar da consciência sobre si mesma como que nos afasta da mortalidade, permitindo-nos viver no universal. Eis o sentido da ética social tão insistentemente defendida por Dilthey. Com ela, julga ele poder defender a universalidade dos princípios morais da ação, reivindicada pela "filosofia da vida", em seu papel de substituir a velha filosofia prática, sem incorrer no erro de tentar aprisioná-los em uma construção a priori da tarefa moral do homem com pretensão de validez universal. Não devemos nos esquecer de que, conforme Dilthey declara em seu Plano de Desenvolvimento para a Construção do Mundo Histórico nas Ciências do Espírito, o último passo para a libertação do homem é dado pela consciência histórica, ao indicar-nos a vida inteiramente "[...] livre do conhecimento por meio de conceitos" e o espírito, "[...] soberano diante de toda teia de aranha do pensamento dogmático" 32 .

\footnotetext{
${ }^{31}$ Cf. Über die Möglichkeit einer allgemeingültigen pädagogischen Wissenschaft, Gesammelte Schriften, VI, 57.

${ }^{32}$ Cf. Gesammelte Schriften, VII, 290-291.
} 
Com efeito, é-nos dado denunciar como naturalmente frágeis e impotentes todas aquelas tentativas de apreender a vida através das tramas totalmente inadequadas e pobres do pensamento. É como se este se caracterizasse por uma natural incompreensão da vida do espírito que flui eternamente na corrente da história. "Essas determinações de fins éticos" - sustenta Dilthey - "[...] contêm uma parte da verdade, também quando ainda na água dos conceitos vazios se dissolve homeopaticamente; mas a própria verdade não está em nenhuma fórmula"33. Pelo que estamos podendo perceber, nenhuma fórmula é suficientemente mágica para conter a verdade absoluta e eternamente infinita. Todas são apenas soluções homeopáticas formadas pela História. As respostas históricas não deixam de ser manifestações homeopáticas da verdade e com isso, é claro, de sua universalidade também.

Cabe-nos, neste ponto, fazer um paralelo entre a validez historicamente limitada das determinações de fins morais e daquela própria das concepções do mundo. Estas, de acordo igualmente com os limites impostos pela filosofia da vida de Dilthey, expressam apenas diferentes visões do universo e são, com isso, unilaterais, o que não as impede de representarem os raios históricos da luz da verdade, já que, para Dilthey, somos como que impedidos de vislumbrar a pura luz da verdade ${ }^{34}$. Em sua "Teoria da Concepção do Mundo" (1911), Dilthey propõe o emprego da consciência histórica na filosofia e na história e desenvolve uma tática verdadeiramente eficaz para combater o relativismo histórico. A consciência histórica levada às últimas consequências consegue vencer a barreira das antinomias ou contradições inerentes às concepções de mundo, as quais defendem, cada uma para si, a validez universal de suas proposições historicamente condicionadas, e alcançam um terreno absolutamente sólido e depurado de toda contradição ou oposição, qual seja, o da própria energia vital, fonte original da infinita multiplicidade de formas vitais que a natureza humana assume, em seu evoluir histórico. Feito esse reconhecimento, basta persistir no exercício de religar cada concepção do mundo à fonte de energia vital que, em vez de detectarmos oposições, contradições e divergências, captamos apenas diferenças, variedade ou multiplicidade de formas de manifestação daquela energia vital original ${ }^{35}$.

Como podemos perceber, em nenhum momento é colocada em jogo a crença do autor de que a verdade existe. Sim, ela, ao exteriorizar-se sob diferentes e variadas formas históricas, dá vida e significado à história da humanidade.

\footnotetext{
33 Pädagogik, Gesammelte Schriften, IX, 176.

${ }^{34}$ Cf. Traum, Gesammelte Schriften, VIII, 224.

${ }^{35}$ Cf. Gesammelte Schriften, VIII, 8.
} 
Todavia, como verdade absoluta, é inapreensível historicamente, quer sob a forma de fins morais, quer de concepção do mundo.

Pretender apreendê-la no seu todo significa, para Dilthey, o mesmo que "[...] com coragem infantil querer esgotar o mar em pequenos copos"36. Essa comparação, como vemos, permite-nos formar uma imagem bastante clara do diagnóstico diltheiano. Revela-nos, até com certa fantasia poética, que se a verdade não nos é acessível em sua totalidade e universalidade, isto se deve à limitação e imperfeição do potencial humano e não a defeito ou falha constitucional da própria verdade. Do mesmo modo, se os recursos humanos históricos são precários e rudimentares para cumprir uma missão tão nobre e elevada, como essa apreensão da verdade absoluta, a comprovação desse fato não invalida, na opinião de Dilthey, nossa crença esperançosa de podermos contar, em cada época, com princípios morais capazes de orientar universalmente nossa conduta humana histórico-social.

Por meio dessas considerações, não nos é difícil compreender que a ética diltheiana seja socialmente formativa, justamente na medida em que ela é como que plasmada de baixo para cima e não construída de cima para baixo, a partir de um conceito de subjetividade inteiramente vazio, antissocial e sem história. Ela busca, com efeito, tendo como base a vida humana histórica real do homem, extrair princípios fundamentais capazes de orientar sua ação em sociedade. Por esse motivo, assevera-nos Dilthey, no primeiro volume de sua obra Vida de Schleiermacher:

Todas as regras, todos os deveres e todas as virtudes podem expressar o comportamento que para o indivíduo nasce do nexo finalista do mundo do espírito, como a humanidade o realiza na história. Este é o mais alto bem [...]. Deveres são somente as regras que são fundadas no fim interior da humanidade para realizar este mais alto bem. Virtudes são somente forças que são tributárias desse fim [...]. No grande nexo desses bens históricos que a humanidade produz para viver e para atuar reside a alegria da vida humana e da perfeição humana. Nossa existência moral tornar-se-ia tão mais perfeita quão mais fundo ela estiver mergulhada nessas objetividades e quão mais compreensivamente nossa atividade interessar-se por elas. ${ }^{37}$.

Como sabemos, o mundo do espírito resulta do exercício por parte da humanidade da ligação teleologicamente orientada entre a vida e história, espírito e vivência. É do nosso conhecimento também que as vivências humanas históricas são constitutivamente animadas pela vida do espírito universal. Nessa verdadeira

\footnotetext{
${ }^{36}$ MISCH, Clara (Org.). Der junge Dilthey, ein Lebensbild in Briefen und Tagebüchern 1852-1870. 2.ed. Göttingen: Dilthey, Vandenhoeck \& Ruprecht, 1960, p. 121.

${ }^{37}$ Gesammelte Schriften, XIV, $1^{\circ}$ vol., 367-368.
} 
simbiose entre o eterno, o infinito e o humano encontram-se formados, ou melhor dizendo, ganham significado vital todas as regras, deveres e virtudes que a humanidade deve respeitar, cumprir e lutar por alcançar como sinal da realização do mais alto bem em seu evoluir histórico. Assim sendo, as regras, os deveres, as virtudes, os bens historicamente registrados são indícios vivos e concretos da manifestação lenta e progressiva da energia infinita do espírito. Ao permitir o seu desvelar, a vida humana conquista sua perfeição e faz jus à alegria. Ora, exteriorizar consciente e criativamente a atuação dessa força infinita em nós é prova conclusiva de quão fundo estamos submetidos aos seus poderes. E tudo que, por influência desse nexo ou dessa ligação vital com essa energia, o homem concretizar historicamente é traduzido para a linguagem filosófica sob o título de objetividades ou objetivações do espírito ou da vida. "Deste mundo do espírito objetivo - declara Dilthey em seu Plano de Desenvolvimento para a Construção do Mundo Histórico nas Ciências do Espírito - nosso próprio ser recebe desde a primeira infância seu alimento"38. Este constitui o verdadeiro e único habitat da vida humana.

\section{OTIMISMO PEDAGógICO E DOMÍNIO DA PEDAgOgIA UNIVERSAL}

Somente nos é possível apreender o significado da vida, se formos capazes de acompanhar aquele balanço dialético inerente à lógica da vida, aquele ritmo pendular que vai da parte ao todo e volta do todo à parte. Assim pulsa a vida e só assim podemos ousar alcançar princípios universalmente válidos de conduta, estando eles ao mesmo tempo irremediavelmente presos a soluções historicamente condicionadas. Afinal, a filosofia diltheiana nos ensinou que a história é o registro humanamente condicionado da manifestação da energia infinita do espírito. Ela é, na verdade, regida pela relação hermenêutica entre o singular e o universal, entre o reino da individualidade e o da regularidade ${ }^{39}$.

Por trás de toda a trajetória filosófica de Dilthey, podemos captar a aceitação tácita do autor de que a própria vida educa. E, se ela é grande mestra da humanidade, cabe ao homem buscar compreendê-la, inclusive em sua profundidade insondável. Esta acaba por constituir a tarefa basilar da "filosofia da vida", na medida em que instrumental e teleologicamente se volta essencialmente para fundamentar uma teoria da formação do homem. E Dilthey procura ser bem explícito, em sua caracterização da vida:

Viver significa: deixar agir sobre si todas as forças do universo, tanto na intuição quanto na atividade, desenvolver todas as tendências do próprio

\footnotetext{
38 Gesammelte Schriften, VII, 208.

${ }^{39}$ Cf. Ideen, Gesammelte Schriften, V, 236.
} 
ser para alcançar um todo harmonioso. Assim nasce a obra de arte de nossa existência. [...] Tudo é em si mesmo singular; sentindo a própria alegria e a própria dor, compreendo o mundo à sua própria maneira, tendo em si mesmo uma fonte de alegria e dores sem fim, de formação e atividade infinitas. Tudo depende exclusivamente de compreender-se a si mesmo, de querer-se a si próprio, inclusive com aquela imagem ideal que se confunde com nosso lugar dentro da ordem do universo ${ }^{40}$.

Como estamos podendo perceber, vida significa antes de mais nada, deixar viver, deixar atuar e agir, com o apoio do poder de apreensão imediata da intuição, a energia do espírito universal. Cada ato do ser vivo deve manifestar essa força que, apesar de atuar uniformemente onde quer que haja vida, não o impede de fazê-lo dentro do mais puro exercício da singularidade que também lhe é peculiar. E assim nasce a obra de arte de cada existência, sustentada pelo equilíbrio dialético entre parte e todo, uniformidade e singularidade, alegria e dor, ideal e real, dever ser e ser, equilíbrio este inerente à própria lógica da vida. O viver é, realmente, uma tarefa essencialmente singular, mas absorve sua energia de uma fonte comum, universal. Nesse sentido, o viver distintivamente humano caracteriza-se pelo exercício autoconsciente desse nexo, dessa ligação ou comunhão vital entre parte e todo. Poderíamos sustentar, portanto, que viver é o mesmo que deixar viver na parte o todo, essa fonte inesgotável de energia que, em troca, anima e dá significado à parte.

Esse viver constitui a expressão máxima da hermenêutica da vida, pela qual Dilthey busca com sua filosofia de vida estabelecer a fundamentação da formação do mundo histórico e de sua compreensão por meio das "ciências do espírito". Propomo-nos acompanhar e analisar mais cuidadosamente os efeitos desse ponto de apoio basilar da hermenêutica da vida para a pedagogia diltheiana. Afinal, nós já sabemos que, na opinião do autor, "a teoria da formação do homem" deve ser sempre a mais pura florescência de uma filosofia que pretende ser autêntica. Dentro dessa tendência natural e legítima de a filosofia desembocar sempre em uma pedagogia, nós procuramos ressaltar que o conceito hermenêutico da vida é o denominador comum capaz de unir filosofia e pedagogia em um nexo fundamental. Tivemos oportunidade de ver quão sólida é essa comunhão entre as duas, quando procuramos mostrar que a própria ética, que auxilia a pedagogia na determinação do fim da educação, e a psicologia, que oferece sua contribuição no sentido de esclarecer o funcionamento e o desenvolvimento dos processos psíquicos vitais, podendo, com isso, apontar os meios da educação, encontram-se inteiramente subordinadas à compreensão da vida. Somente graças a essa penetração funda,

\footnotetext{
${ }^{40}$ Der junge Dilthey, p. 117.
} 
aparentemente insondável das raízes do conceito diltheiano de vida, nos é dado compreender o otimismo que a "filosofia da vida" e, consequentemente, a pedagogia ou teoria da formação do homem nos transmitem.

De fato, a vida, compreendida inclusive em sua profundidade, tem por constituição o poder virtual de educar a humanidade. Aliás, essa é a tarefa mais autenticamente vital. "Por educação" - declara Dilthey - "[...] nós entendemos a atividade planejada por meio da qual o adulto procura formar a vida psíquica do ser em crescimento" ${ }^{41}$. O sucesso de tal atividade encontra-se fundamentalmente garantido pela própria estrutura constitucional da vida psíquica. Ao afirmar que o nexo psíquico é imanentemente teleológico, Dilthey já está assegurando não apenas a possibilidade de desenvolvimento do ser humano, seu direito natural à educação, como também a necessidade da educação. Contudo, possibilidade, necessidade, direito são expressões ainda muito gerais para apreender o significado essencial que a educação tem para a vida, enquanto aquela estrutura imanentemente teleológica.

Trata-se, no fundo, de uma necessidade essencial do homem de ser o que é, ou o que deve ser. Veremos mais adiante que, dentro do cenário do pensamento diltheiano, não há nenhuma ruptura, brecha ou descontinuidade entre ser e dever ser. Na verdade, essa necessidade encerra uma exigência natural do ser que clama por desenvolvimento. É como se uma força interior o impelisse a cumprir seu destino vital, qual seja, o de manifestá-la, exteriorizá-la, desvelá-la ainda que seja singular e historicamente. Cada ato do ser humano passa, então, a carregar em si uma consciência protetora dessa unidade original, sendo que a sociedade é o símbolo vivo e autêntico dessa comunhão do singular com o universal, das partes com o todo. "O indivíduo" - proclama Dilthey - "[...] recebe, durante sua preparação, influências de todos os círculos da vida social. [...] Ele respira na família, na igreja, na vida científica, no nexo sócio-político. Ele vive desde o princípio em relações vivas. Ninguém deve querer bloqueá-lo. A educação deve somente guiá-lo e formá-lo durante esse processo" ${ }^{42}$. As influências que o homem sofre da vida em sociedade ou, de acordo com a denominação diltheiana, do mundo do espírito objetivo, em que desde o nascimento se encontra mergulhado, constituem sua alimentação vital. Essa comunhão entre o indivíduo e "o meio das coisas comuns" deve naturalmente estreitar-se como sinal de crescimento ou, para usar as palavras do autor, de "alargamento do sentimento pessoal de vida". A importância desse entrelaçamento é tão vital que Dilthey o erige à categoria de princípio básico de sua pedagogia. Ele chega mesmo a declarar que o princípio da

\footnotetext{
${ }^{41}$ Pädagogik, Gesammelte Scbriften, IX, 190.

${ }^{42}$ System der Ethik, Gesammelte Schriften, X, 119.
} 
pedagogia se encontra na identidade da vida psíquica em desenvolvimento com as formas da vida histórico-social ${ }^{43}$.

A nosso ver, o princípio fundamental da pedagogia diltheiana é uma nova versão, a versão pedagógica da lógica da vida inteiramente comprometida com o balanço dialético parte-todo. A identidade entre objetivo do desenvolvimento pessoal e vida social constitui o grande princípio educacional, segundo as palavras do autor, "[...] o princípio real que torna possível a educação" ", somente porque, voltamos a insistir, essa unidade entre parte e todo, individualidade e totalidade, singularidade e universalidade já está dada originalmente com a própria vida. Como sabemos, as criações do mundo histórico absorvem dessa unidade original sua objetividade ou seu caráter de universalidade. Só secundariamente passam as grandes forças objetivas, que a história da humanidade nos apresenta, a constituir o ponto de partida da formação e da compreensão do mundo histórico por parte das "ciências do espírito". Se isso acontece é porque originalmente elas nada mais são do que manifestações ou exteriorizações de uma energia primitiva, absolutamente incondicionada.

Nesse sentido, a saber, dentro do balanço pendular parte-todo, o aperfeiçoamento do indivíduo passa a ser visto sob o ângulo mais amplo e universalizante do aperfeiçoamento da humanidade. Com efeito, dentro da perspectiva diltheiana, o ofício de viver é tão essencialmente sagrado que seria profaná-lo, se o supuséssemos inteiramente subjugado à pequenez do desenvolvimento de indivíduos particulares. Mais do que isso, o próprio indivíduo encerra em si exigências e anseios da humanidade, e assim sua particularidade nos faz apenas evocar sua ligação com o todo.

Aquilo que Dilthey denomina perfeição apenas formal dos processos psíquicos particulares é, na opinião dele, toda a esfera da pedagogia universal ${ }^{45}$. Sob a mira dessa perspectiva, assim tão bem delimitada, torna-se possível descrever o processo educacional em sua perfeição formal, derivar-se regras ou normas pedagógicas. Todavia, o autor reconhece ser esse tratamento "[...] uma abstração da vitalidade histórica do homem" ". Em um primeiro momento, nós temos que concordar que se trata de um formalismo, de uma abstração, porque, para o autor, quando deixamos a esfera da perfeição formal e sua descrição científica, adentramos a da realidade pedagógica ou dos processos educacionais,

\footnotetext{
${ }^{43}$ Cf. Ibid., 118.

${ }^{44}$ Cf. Ibid.

${ }^{45}$ Cf. Über die Möglichkeit einer allgemeingültigen pädagogischen Wissenschaft, Gesammelte Schriften, VI, 68-69.

46 Cf. Ibid., 68.
} 
com seus contornos bem definidos no espaço e no tempo, o que prontamente nos alerta para o fato de não estarmos mais dentro dos limites estreitos da mais pura universalidade formal da pedagogia, aliás, a única admitida por Dilthey. Vejamos de que modo ele resume esse seu ponto de vista:

A condição mais geral de regras e normas universalmente válidas da vida psíquica, dos sistemas culturais que se baseiam nelas, especialmente o da educação, encontra-se no caráter teleológico da vida psíquica. O princípio fundamental de uma pedagogia consiste, pois, em uma afirmação: "a vida psíquica tem uma finalidade intrínseca, portanto uma perfeição que lhe é própria [...] Conseqüentemente, é possível dar-se normas dessa perfeição, traçar regras de como essa perfeição pode ser alcançada pela educação ${ }^{47}$.

Trata-se, ao que tudo indica, de novo rótulo para aquela velha e conhecida unidade parte-todo, individualidade-totalidade, singularidade-universalidade, história-soberania do espírito, nexos estes originalmente dados com a própria vida. Com efeito, a vida psíquica desenvolve-se de acordo com uma teleologia que lhe é imanente, a saber, ela tem uma tendência finalista, Isso quer dizer que traz em si o gérmen da sua própria perfeição. Aqui parece, de fato, residir o sentido mais profundo de toda a tônica fortemente otimista da pedagogia diltheiana. O que pode, porém, confundir-nos num primeiro momento é justamente a afirmação categórica do autor de que se trata de uma possibilidade apenas formal de perfeição. Esta, na realidade, não nos permitiria nutrir nem mesmo a mais torpe confiança na capacidade de aperfeiçoamento real e concreto do ser humano histórico. O que dizer, então, da convicção tão forte e tão vigorosa de que essa possibilidade é real e verdadeira, convicção essa que Dilthey deixa transparecer em sua "filosofia da vida"? Onde lançará ela seus tentáculos mais profundos e menos visíveis? O que Dilthey denomina perfeição formal é, na verdade, a perfeição própria da energia original que, ao penetrar as criações históricas, se manifesta por meio delas, garantindo-lhes vida... Por isso, vida significa, como sabemos, desenvolvimento, teleologia e perfeição. Fechando o círculo mais uma vez: essas três qualidades essenciais da vida só podem ser detectadas pela categoria do significado que nos impõe, por seu turno, o estabelecimento de um tipo especial de relação do todo com suas partes, da energia infinita do espírito com suas criações históricas, da vida com as vivências...

Uma vida psíquica, tão sólida e confortavelmente apoiada pela energia universal do espírito, pode oferecer-nos a vantagem de atuar teleologicamente ou, o que é a mesma coisa, é dotada da tendência para realizar "o fim como motivo". $\mathrm{Na}$ verdade, se a história do espírito humano traduz, no fundo, o modo como a

\footnotetext{
${ }^{47}$ Pädagogik, Gesammelte Schriften, IX, 185.
} 
energia universal se manifesta ou se desvela em suas criações singulares e concretas, não importa quais sejam os fins específicos e historicamente condicionados cumpridos por elas, pois estes estarão de qualquer forma sempre subordinados "ao fim como motivo", que submete as vontades particulares a realizar "o que é preciso". Afinal, como é do nosso conhecimento, tudo que se efetiva em termos de realidade humana histórico-social tem como mola propulsora a vontade, e nesta atua "[...] o fim como motivo" ". Conforme estamos percebendo, o fim em questão é o próprio desvelar da energia originária, único motivo autêntico da vida humana histórico-social. Ele atua como um verdadeiro cordão invisível a garantir o sentido positivo da marcha da história humana universal. Ora, dizer que esse fim simboliza a perfeição máxima significa também que ele tem condições de potencialmente motivar o aperfeiçoamento histórico-social do homem.

Torna-se, assim, fácil compreender a tônica otimista da postura éticopedagógica de Dilthey, apesar de sua insistência em defender com todo rigor a possibilidade apenas formal de perfeição da vida psíquica e o condicionamento histórico não só de todo sistema ético e de toda pedagogia, mas fundamentalmente de todo produto ou criação humana do espírito. Ao buscarmos compreender a "filosofia da vida", somos levados a afirmar que a defesa diltheiana da historicidade de todo fenômeno humano não compromete, de maneira alguma, o caráter universal da pedagogia no desempenho de seu papel fundamental de teorizar a formação do homem, ontem, hoje e sempre.

Em outras palavras, o condicionamento histórico de todo fim da educação, tão categoricamente afirmado por Dilthey, deve representar, para nós, apenas o modo especial particular e concreto de a energia infinita do espírito manifestarse. Essas exteriorizações são, com efeito, condicionadas historicamente, mas não nos devemos esquecer de que elas são meros registros ou sinais concretos do desvelar lento e progressivo daquela energia originalmente infinita. Poderíamos enfatizar que os fenômenos históricos são frações da verdade e que, enquanto tal, cada um deles é universalmente verdadeiro no tempo e lugar em que ocorre. Assim, parece ser possível ao autor defender, de um lado, o condicionamento histórico das criações humanas do espírito e, ao mesmo tempo, salvaguardar a possibilidade de que elas possam, enquanto oriundas da verdade universal, valer também universalmente, pelo menos enquanto manifestarem vida...

Aqui se incluem os fins da educação que a ética deve extrair do fim da vida. Estes, como sabemos, são condicionados historicamente, fato que, conforme estamos procurando mostrar, não os impede de valer universalmente. Só não podem ser determinados a priori com pretensão de validez universal, pois

${ }^{48}$ Cf. Gesammelte Schriften, I, 53. 
cada um deles corresponde apenas a um curto momento do desenrolar lento e progressivo da energia original - e esta, como vimos, não se deixa apreender em nenhuma fórmula por mais mágica que possa parecer. "Não há" - declara Dilthey - "[...] nenhuma ciência pedagógica universal a partir da qual seja possível decidir o regulamento das questões do ensino para todos os povos e tempos" De fato, as questões ligadas ao ensino estão como que inevitavelmente presas às particularidades históricas de um determinado povo em uma determinada época e não podem obter respostas definitivas e absolutamente válidas, mas, enquanto tais, trazem sempre consigo sabor de universalidade. Poderíamos asseverar que cada pedagogia é um momento histórico concreto e singular da manifestação do espírito universal e dentro dessa perspectiva faz jus ao caráter de universalidade. Afinal, nós não poderíamos pretender compreender a vida e a história, sem nos deixarmos levar por esse balanço dialético que lhe é inerente.

Como estamos podendo perceber, não se trata da admissão de uma perfeição meramente formal, mas de uma garantia verdadeiramente sólida de que a "filosofia da vida", enquanto filosofia fundamentalmente prática, poderá nos oferecer princípios capazes de orientar universalmente a conduta humana histórica. Não importa que tais princípios estejam sujeitos a interpretações históricas do dever ser, pois já fomos suficientemente alertados para o fato de que a história nada mais é do que o desenrolar lento e progressivo do espírito universal. E justamente dentro de tal perspectiva é possível a Dilthey afirmar que encontra no ser a razão do dever ser. De fato, o que deve ser permeia, como um verdadeiro cordão invisível, a realidade histórico-social e, ao conduzi-la, emprestalhe o caráter de necessidade universal. Se a história representa a manifestação da verdade universal, cada momento da realidade histórico-social tem sua verdade universalmente garantida.

Nesse sentido, a tarefa de descrever ou analisar a realidade histórico-social, tarefa esta tão cara às "ciências do espírito" em seu conjunto, não se resume em dizer apenas como essa realidade é, pois o que é se encontra, na opinião do autor, indissoluvelmente ligado ao que deve ser. "Ver o real" - afirma Dilthey “[...] está ligado, pois, com uma idéia de perfeição. O que é mostra-se como algo indissolúvel daquilo que vale e que deve ser. Assim incluem-se nos fatos da vida as normas deles mesmos" ${ }^{\prime \prime}$.

\footnotetext{
${ }^{49}$ Die Frage des höheren Unterrichts und die pädagogische Wissenschaft. In: GROOTHOFF, HansHermann; HERRMANN, Ulrich (Org.). Wilhelm Diltheys Schriften zur Pädagogik. Paderborn: Ferdinand Schöningh, 1971, p. 129.

50 Abhandlung von 1895, Gesammelte Schriften, V, 297.
} 
Com essas considerações, torna-se mais claro para nós que a perfeição própria da vida psíquica não pode apenas ser vista como a condição formal mais geral da educação, como defende Dilthey, ao tentar escapar de suas próprias críticas aos sistemas pedagógicos com pretensão de validez universal. Se o que é, o é porque vale, como pode o autor admitir que concebe a universalidade apenas enquanto restrita às fórmulas abstratas, vazias de conteúdo, sem vida, portanto? $\mathrm{E}$ o que dizer do vigor da energia original que a tudo permeia? Insistimos em perguntar: trata-se, realmente, de uma universalidade apenas formal, ou esse aparente formalismo é somente o manto protetor daquela fé viva e atuante do autor na unidade original, fonte absoluta de garantia do significado universal de cada momento singular da realidade histórico-social?

Com os olhos voltados para esse "fervoroso filósofo do espírito" que insistimos em descobrir por trás daquele "arguto historiador do espírito", conforme era apontado pelos seus contemporâneos, nós julgamos poder responder devidamente às críticas de Otto Willmann e de Herman Nohl. Willmann, conforme ressaltamos no início deste texto, mostra-se inconformado com a indefinição e falta de vigor daquilo que Dilthey reconhece como pedagogia universal. Nohl parece também não poupar o mestre de uma crítica bastante severa a sua postura pedagógica. Em sua opinião, Dilthey defendeu para a sua pedagogia uma universalidade tão rigidamente formal que, "[...] se refletirmos bem, essa pedagogia não pode sequer nos dizer se ela forma perfeitos criminosos, ou homens perfeitamente bons" ${ }^{\text {. }}$. As críticas de Willmann e Nohl são, no fundo, bastante pesadas, principalmente se tivermos em mente que Dilthey é um filósofo defensor do valor instrumental da filosofia para gerar, como resultado mais elevado de suas investigações, uma "teoria da formação do homem" ou uma pedagogia. Assim, se nós tomarmos os conceitos e afirmações do autor apenas no seu sentido literal, somos obrigados a admitir a pertinência de ambas as críticas.

Procuramos acompanhar o balanço dialético, próprio da lógica da vida, e assim insistir sempre no exercício daquela relação especial, inerente à categoria do significado, a saber, a relação parte-todo. É no balanço equilibrado das partes com o todo que conseguimos reunir argumentos para salvar a pedagogia diltheiana de críticas tão sérias e pesadas. Ora, cumprir à risca essa tarefa significou para nós salvaguardar o caráter de universalidade inerente ao conceito diltheiano de vida e, consequentemente, próprio dos princípios ético-educacionais capazes de orientar os atos humanos histórico-sociais. De posse desse resultado positivo, tornou-se compreensível para nós a tônica sempre otimista da postura pedagógica de Dilthey, a despeito de insistir literalmente na historicidade dos sistemas éticos

\footnotetext{
${ }^{51}$ NOHL, Herman. Die Pädagogische Bewegung in Deutschland und ibre Theorie. Frankfurt am Main: Verlag
} G. Schulte-Bulmke, 1970, 1.112. 
e pedagógicos e no formalismo árido e sem vida da perfeição da vida psíquica. Agora, temos consciência clara do significado das seguintes palavras do autor: "Na natureza da vida reside acima de tudo a tendência para a cada momento saciar-se com a plenitude do valor" ${ }^{52}$. A vida vale absolutamente, a sua perfeição lhe é imanente e a história humana nada mais é do que o processo universal de exteriorização dessa perfeição, desse valor, dessa verdade absoluta. Assim sendo, o devir histórico não nos amedronta com a insegurança ou a incerteza de um futuro próximo ou mesmo distante, mas, pelo contrário, nos conforta com a esperança justificadamente otimista de que a vida vale absolutamente.

A poesia de Goethe representa, na opinião de Dilthey, o cumprimento dessa tarefa, que a filosofia somente muitos anos depois conseguiu realizar, qual seja: "A unidade da vida e do ideal, a identidade eterna, a realização da razão do mundo na vida da história" ${ }^{3}$. Aqui parece alojar-se o comprometimento essencial da filosofia diltheiana da vida com o credo professado pelo então "fervoroso filósofo do espírito".

Dilthey não precisou, como Kant o fez, defender o valor absoluto da boa vontade para fundar universalmente o agir humano moral. Como substituto à altura, ele procurou fundamentar objetivamente sua crença na unidade original, envolvendo todo esse conteúdo sob o rótulo científico-protetor da "teleologia imanente da vida psíquica". O que importa é que esta exerceu, como procuramos indicar, o papel de "poder regulador da consciência universal" a orientar como uma "força uniforme" a ação humana histórico-social ${ }^{54}$. Essa teleologia imanente à vida projeta na história seu caráter de processo que evolui necessariamente em direção ao cumprimento de um fim, motivo universal da humanidade.

Esse fim ou motivo é Deus, conforme podemos apreender a seguir, a partir das próprias palavras do autor:

Tão imperfeita quanto a idéia de um embrião, no qual é dada uma força prodigiosa, da qual a árvore se desenvolve, constituindo como que uma lei hipostática, condensada num único ponto, em vez de visualizá-la na infinitude da vida com sua atuação infinita - tão imperfeita e correspondendo àquela é a idéia de alguns seres dos quais, com a graça divina, emana a verdade, por força de um impulso irreprimível que vem de Deus. A lei, ao contrário, está presente e atuante em toda parte, do mesmo modo e em qualquer lugar. Apesar disso, é possível deduzir as formas dos seres orgânicos somente a partir desta lei, mas esta lei possui uma finalidade divina. É assim também neste caso. E há mais. Não é como um espelho côncavo em que se cruzam os movimentos do

\footnotetext{
52 Ideen, Gesammelte Schriften, V, 219.

${ }^{53}$ Der junge Dilthey, p. 5.

54 Cf. Gesammelte Schriften, I, 63 e VIII, 180.
} 
mundo nos indivíduos fazendo com que surjam novas idéias e concepções do mundo, antes deve existir algo divino na alma que se entrega a essas influências, ou seja, uma pureza de vontade, uma energia do bem, um senso dirigido à essencialidade profunda e eterna que encerra justamente o elemento divino ${ }^{55}$.

Ousaríamos afirmar que se trata de uma passagem única, pela forma densa, intrincada, profunda e, ao mesmo tempo, dentro de uma sequência longa em que Dilthey confessa sua profunda fé na unidade divina. É como se, em verdade, Dilthey deixasse por um momento falar livremente sua inclinação natural, sua fé profundamente intuída, como em um verdadeiro desabafo incontido de quem, como filósofo, impôs para si a tarefa de viver na mais completa objetividade de pensamento. Desse modo, o "empírico obstinado" deixa, talvez como em nenhum outro momento de sua peregrinação filosófica, transparecer claramente o "fervoroso filósofo do espírito" que o sustenta sólida e profundamente. O caráter enfático que deu ao concreto, ao empírico e ao prático, em seus escritos, parece justamente advir de uma necessidade natural mais profunda de defender uma fé que sabia ser apenas um sinal de sua fraqueza humana. Como filósofo, deveria aceitar, como sabemos, apenas as crenças que se sustentassem diante do pensamento. No entanto, seu pensamento, inteiramente comprometido com essa marca de nascença, seguiu seu caminho, conforme procuramos mostrar, sempre assessorado, ora de perto, ora de longe, por essa fé. E, se "deve existir algo divino", "uma pureza de vontade", "uma energia do bem", "um senso dirigido à essencialidade mais profunda e eterna que encerra justamente o elemento divino", então, nós podemos responder a Nohl que a pedagogia diltheiana, assim tão sólida e profundamente fundada, só poderá formar "homens perfeitamente bons". E a Willmann, cabe-nos ponderar que o que lhe pareceu indefinição e falta de vigor, dentro da concepção diltheiana de pedagogia universal, resume-se apenas em dificuldades inerentes à passagem da fé intuída à razão, ou da crença ao pensamento objetivo, dificuldades essas que povoam a história da filosofia. E o poder eficaz dessa compreensão da hermenêutica da vida parece nos provar que o vigor da "filosofia da vida" de Dilthey, como substituta da velha filosofia prática, revelou estar diretamente proporcional à crença fervorosa que o autor nutre pela história universal da humanidade, como manifestação lenta e gradativa da unidade original, ou Deus.

${ }_{55}$ Der junge Dilthey, p. 155. 
PACHECO AMARAL, Maria Nazaré de Camargo. Dilthey: The hermeneutics of life and the universal aspirations of pedagogy. Trans/Form/Ação, Marília, v. 35, n. 1, p. 89-114, Jan./ Abril, 2012.

\begin{abstract}
Dilthey claimed that first psychology and then hermeneutics played the foundational role for his philosophy of life, whose main practical goal is to develop a pedagogy or theory of education. Pedagogy needs help from ethics to establish its ends, and from psychology to indicate its means. This paper intends to show the relationship between Dilthey's hermeneutics of life and his pedagogy. Dilthey's philosophy of life, in so far it adopts the hermeneutical procedure, engages in the understanding of, or the search for the meaning of, human socio-historical creations, by adopting a special type of relationship between parts and whole. It is exactly within this hermeneutical balance that we propose to extinguish any indication of a rupture, breach, or contradiction between the quest for universal principles of human behavior and Dilthey's defense of the impossibility of constructing human moral tasks by means of universal principles. Dilthey began his ethics lectures at the University of Berlin in 1890. These lectures, published in 1958 by Herman Nohl in volume $\mathrm{X}$ of Dilthey's collected works, indicate the direction of the trajectory by which formative or social ethics are consolidated as a historical solution for reaching universal principles that can guide human purposes. This trajectory is a result of the distinctively human exercise of self-reflection, by means of which we can fulfill our destiny of manifesting and exteriorizing in time the immanent energy of the absolute spirit. We wish to show that it is possible that such a pedagogy can respect its universal task of orienting the historical development of the younger generation without directing this process by means of fixed and rigid aims.
\end{abstract}

KEYWORDS: pedagogy; self-reflection; formative ethics; philosophy of life; hermeneutics.

\title{
REFERÊNCIAS
}

AMARAL, M. Nazaré C. P. Philosophie der Philosophie: ein wirksames Pflaster zur Heilung der vom historischen Relativismus geschlagenen Wunde?” In: RODI, Frithjof (Org.). Dilthey-Jahrbuch für Philosophie und Geschichte der Geisteswissenschaften, vol. VI. Göttingen: Vandenhoeck \& Ruprecht, 1983.

DILTHEY, Wilhelm. Abhandlung von 1895. In: Gesammelte Schriften, vol. V.

- Das geschichtliche Bewusstsein und die Weltanschauungen". In:

Gesammelte Schriften, vol. VIII.

Einleitung. In: Gesammelte Schriften, vol. I.

Ideen. In: Gesammelte Schriften, vol. V.

Leben und Erkennen. In: - Gesammelte Schriften, vol. XIX.

Logik und System der philosophischen Wissenschaften. In: Gesammelte Schriften, vol. XX. 
Pädagogik, Geschichte und Grundlinien des Systems. In: Gesammelte Werke, vol. IX.

. System der Ethik. In: Gesammelte Schriften, vol. X.

. Traum, Gesammelte Schriften. In: . vol. VIII.

. Über die Möglichkeit einer allgemeingültigen pädagogischen Wissenschaft. In: - Gesammelte Schriften, vol. VI.

. Übersicht meines Systems. In: - Gesammelte Schriften, vol. VIII.

GROOTHOFF, Hans-Hermann; HERRMANN. Ulrich (Org.). Wilhelm Diltheys Schriften zur Pädagogik, Paderborn: Ferdinand Schöningh, 1971.

HARTONG, Konrad. Der Begriff der "paedagogia perennis" und die Auseinandersetzung Otto Willmanns mit Wilhelm Dilthey. Paedagogica Histórica, 3. Jg., Gent, 1963.

HERMANN, Ulrich. Die Pädagogik. Wilhelm Diltheys. Ihr wissenschaftstheoretischer Ansatz in Diltheys Theorie der Geisteswissenschaften. Göttingen: Vandenhoeck \& Ruprecht, 1971.

MISCH, Clara (geb. Dilthey) (Org.). Der junge Dilthey, ein Lebensbild in Briefen und Tagebüchern 1852-1870. 2.ed. Göttingen: Vandenhoeck \& Ruprecht, 1960, p. 121.

NOHL, Herman. Die Pädagogische Bewegung in Deutschland und ihre Theorie. Frankfurt am Main: Verlag G. Schulte-Bulmke, 1970.

1963.

(Org.). Kleinepädagogische Texte, caderno 3, 1. ed., Langensalza,1930; 4. ed. Weinheim,

WILHELM, Theodor: Pädagogik der Gegenwart. 3.ed. Stuttgart: Kröner Taschenausgabe , vol. 248, 1963.

WILLMANN, Otto: Die Fundamentalbegriffe der Erziehungswissenschaft. 1. Jahrbuch für christliche Eriiehungswissenschaft, Kempten, 1908.

Recebido em: 03.10.2011

Aprovado em: 28.11.2011 